\title{
Performance Comparison of Matrix Converter fed Induction Motor Drive using PI and PID Control
}

\author{
Abhijit Mandal $^{1}$, Manoj Kumar Nigam ${ }^{2}$ \\ ${ }^{1}$ (M.E.[Power Electronics] Scholar, Raipur Institute of Technology, Raipur[C.G.], India - 492101) \\ ${ }_{2}^{2}$ (Department of Electrical Engineering, Raipur Institute of Technology, Raipur[C.G.], India - 492101)
}

\begin{abstract}
This paper presents the comparison of performance between PI and PID control scheme of Matrix Converter fed Induction Motor Drive. For the performance comparison modeling and simulation is done for both PI and PID control scheme of Matrix Converter, controlling the Induction Motor Drive. Simulation model consists a three phase matrix converter, an induction motor, a field oriented controller and a power supply. Venturini's modulation algorithm is used for simulation model. The algorithm of Venturini provides unity displacement factor in the input regardless of the load displacement factor and it can be easily implemented in the closed loop operation. Simulation results are presented for the output of converter for both controlling scheme. The result shows that the performance of matrix converter fed induction motor drive using PID control is better than the PI control scheme.
\end{abstract}

Keywords - Field oriented control, Induction Motor, Matrix Converter, PI control, PID control

\section{INTRODUCTION}

The a.c. to a.c. matrix converter was first investigated by Gyugyi and Pelly in 1976 [1]. Venturini and Alesina have introduced a matrix converter design using a generalized high frequency switching strategy [2]. Matrix converters as induction motor drivers became popular in recent years because of its good alternative to voltage-source inverter pulse width modulation (VSI-PWM) converters. The popularity of matrix converter as induction motor driver is because of benefits like bidirectional power flow, simple topology, provides sinusoidal voltage at the load side, sinusoidal input current with adjustable displacement angle (i.e. controllable input power factor), and a great potential for size reduction due to the lack of dc-link capacitors for energy storage [3$6]$.

The physical realization of the matrix converter is not straightforward, due to the fact that there are no freewheeling paths. In addition, the number of devices in the power circuit is high compared with that in the inverter. Consequently, the timing of the switch actuation signals is particularly critical, and protection of the circuit under fault conditions requires very careful consideration [7]. In [8], a highly compact converter using novel high-power 3-in-1 integrated power modules was used. In another paper, the integration of the matrix converter and the induction motor in a single unit was discussed [9].

The first matrix converter contained in a single power module using insulated gate bipolar transistor technology was presented in [10]. There is now competition between the matrix converter and the voltagesource inverter with a regenerative input rectifier. Only a few technical papers have dealt with the dynamic behaviour analysis of the field-oriented controlled matrix converter motor drive. In $[11,12]$, a simulation of the matrix converter feeding an induction motor was performed. and in [13], a control technique for compensating the effects of the input voltage variations on the matrix converter algorithms was described, but closed loop operation was not considered. Closed loop operation has become an important issue for the viable application of matrix converters $[14,15]$. In this paper first modelling and simulation is done for matrix converter using PI(Proportional Integral) and PID(Proportional Integral Derivative)control. After that result were compared between these two scheme.

\section{MATRIX CONVERTER}

The matrix converter consists of nine bi-directional switches, arranged as three sets of three so that any of the three input phases can be connected to any of the three output lines, as shown in Fig. 1, where uppercase and lowercase letters are used to denote the input and output, respectively. Each of these bi-directional switches can be constructed by power semiconductor devices as shown in Fig. 2. Traditionally, two IGBTs with antiparalleled diodes are connected in series to construct one bi-directional switch (Fig. 2a). However, this structure requires 18 IGBTs and 18 diodes, resulting in much more power loss than in conventional AC-DC-AC converters and hindering the further popularization of the matrix converter. Newly developed IGBT with reverse blocking capability (RB-IGBT) helps to resolve this problem. A bi-directional switch is realized by a simple placing of two RB-IGBTs in anti-parallel while 18 diodes used for blocking the voltage in matrix converter are no longer required (Fig. 2b). 




Fig. 1 Schematic block diagram representation Matrix Converter
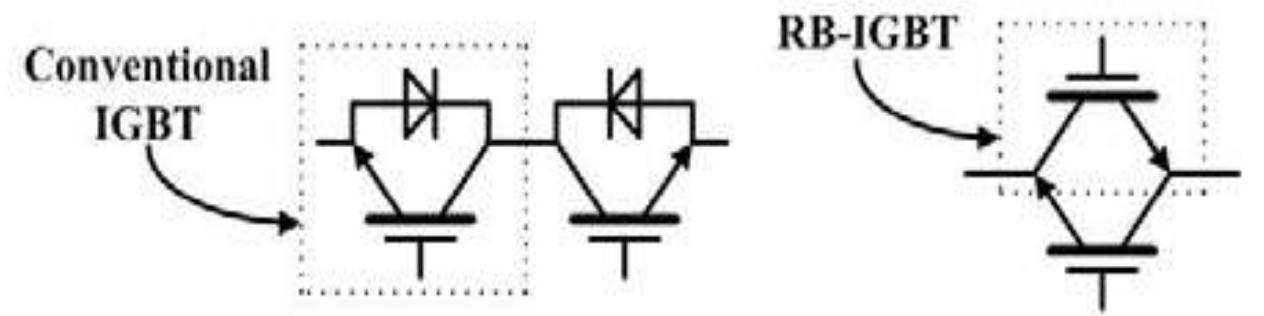

Fig. 2. Two structures of bi-directional power switches: (a) Conventional IGBTs with diodes

(b) RB-IGBTs

The switches of matrix converter are controlled in such a way that the average output voltages are a three-phase set of sinusoids of the required frequency and magnitude [16]. The matrix converter can comply with four quadrants of motor operations, while generating no higher harmonics in the three-phase a.c. power supply. Compared with conventional drives, there is potential for reduced cost of manufacture and maintenance, and increased power/weight and power/volume ratios. The circuit is inherently capable of bi-directional power flow and also offers virtually sinusoidal input current, without the harmonics usually associated with present commercial inverters.

\section{ALgORIthM OF MATRIX CONVERTER}

A simplified version of the Venturini algorithm is used in this work [17]. This algorithm is defined in terms of the three-phase input and output voltages at each sampling instant and is convenient for closed loop operations. For the real-time implementation of the proposed modulation algorithm, it is required to measure any two of three input line-to-line voltages. Then, $\mathrm{V}_{\mathrm{im}}$ and $\omega_{\mathrm{i}} \mathrm{t}$ are calculated as

$$
\begin{aligned}
& v_{\mathrm{im}}^{2}=\frac{4}{9}\left(v_{A B}^{2}+v_{B C}^{2}+v_{A B} v_{B C}\right) \\
& \omega_{\mathrm{g}} t=\arctan \left(\frac{v_{B C}}{\sqrt{3}\left(\frac{2}{3} v_{A B}+\frac{1}{3} v_{B C}\right)}\right)
\end{aligned}
$$

where $\mathrm{v}_{\mathrm{AB}}, \mathrm{v}_{\mathrm{BC}}$ are the instantaneous input line voltages. The target output peak voltage and the output position are calculated as

$$
\begin{aligned}
& v_{\mathrm{om}}^{2}=\frac{2}{3}\left(v_{a}^{2}+v_{b}^{2}+v_{c}^{2}\right) \\
& \omega_{0} t=\arctan \left(\frac{v_{b}-v_{c}}{\sqrt{3} v_{a}}\right)
\end{aligned}
$$

where $\mathrm{v}_{\mathrm{a}}, \mathrm{v}_{\mathrm{b}}, \mathrm{v}_{\mathrm{c}}$ are the target phase output voltages. Alternatively, in a closed loop system (for example a fieldoriented controlled drive), the voltage magnitude and angle may be direct outputs of the control loop.

Then, the voltage ratio is calculated as 


$$
q=\sqrt{\frac{V_{\mathrm{om}}}{V_{\mathrm{im}}^{2}}}
$$

where $\mathrm{q}$ is the desired voltage ratio, and $\mathrm{V}_{\mathrm{im}}$ is the peak input voltage.

Triple harmonic terms are found

$$
\begin{aligned}
& K_{31}=\frac{2}{9} \frac{q}{q_{\mathrm{m}}} \sin \left(\omega_{\mathrm{i}} t\right) \sin \left(3 \omega_{\mathrm{i}} t\right) \\
& K_{32}=\frac{2}{9} \frac{q}{q_{\mathrm{m}}} \sin \left(\omega_{\mathrm{i}} t-\frac{2 \pi}{3}\right) \sin \left(3 \omega_{\mathrm{i}} t\right) \\
& K_{33}=-\sqrt{V_{\mathrm{m}}^{2}}\left[\frac{1}{6} \cos \left(3 \omega_{\mathrm{o}} t\right)-\frac{11}{4 q_{\mathrm{m}}} \cos \left(3 \omega_{\mathrm{i}} t\right)\right]
\end{aligned}
$$

where $\mathrm{q}_{\mathrm{m}}$ is the maximum voltage ratio (0.866).

Then, the three modulation functions for output phase a are given as

$$
\begin{aligned}
& M_{A a}=\frac{1}{3}+k_{31}+\frac{2}{3 V_{\text {im }}^{2}}\left(v_{a}+k_{33}\right)\left(\frac{2}{3} v_{A B}+\frac{1}{3} v_{B C}\right) \\
& M_{B a}=\frac{1}{3}+k_{32}+\frac{2}{3 V_{\text {in }}^{2}}\left(v_{a}+k_{33}\right)\left(\frac{1}{3} v_{B C}-\frac{1}{3} v_{A i}\right) \\
& M_{C a}=1-\left(M_{A a}+M_{B a}\right)
\end{aligned}
$$

The modulation functions for the other two output phases, $b$ and $c$ are obtained by replacing $v_{b}$ and $v_{c}$ with $v_{a}$, respectively in Equations (9) and (10). Note that the modulation functions have third harmonic components at the input and output frequencies added to them to produce output voltage, $\mathrm{v}_{\mathrm{o}}$. This is a requirement to get the maximum possible voltage ratio [7]. It should be noted that in Eq. (3) there is no requirement for the target outputs to be sinusoidal. In general, three phase output voltages and input currents can be defined in terms of the modulation functions in matrix form as

$$
\begin{aligned}
& v_{\text {oph }}=M v_{\text {iph }} \\
& {\left[\begin{array}{l}
v_{a} \\
v_{b} \\
v_{c}
\end{array}\right]=\left[\begin{array}{lll}
M_{A a} & M_{B a} & M_{C a} \\
M_{A b} & M_{B b} & M_{C b} \\
M_{A c} & M_{B c} & M_{C c}
\end{array}\right]\left[\begin{array}{l}
v_{A} \\
v_{B} \\
v_{C}
\end{array}\right]} \\
& i_{\mathrm{iph}}=M^{\mathrm{T}} i_{\mathrm{opb}} \\
& {\left[\begin{array}{l}
i_{A} \\
i_{b} \\
i_{C}
\end{array}\right]=\left[\begin{array}{lll}
M_{A a} & M_{A b} & M_{A c} \\
M_{B a} & M_{B b} & M_{B c} \\
M_{C a} & M_{C b} & M_{C}
\end{array}\right]\left[\begin{array}{l}
i_{a} \\
i_{b} \\
i_{c}
\end{array}\right]}
\end{aligned}
$$

where the superscript $\mathrm{T}$ denotes a transpose, and $\mathrm{M}$ is the instantaneous input-phase to output-phase transfer matrix of the three-phase matrix converter. $v_{\text {iph }}$ and $v_{\text {oph }}$ are the input and output phase voltage vectors, and $i_{\text {iph }}$ and $i_{\text {oph }}$ represent the input and output phase current vectors. Alternatively, from Equations (12) and (13), the output-line voltages and input-line currents can be expressed as

$$
\begin{aligned}
& v_{\text {oLine }}=m v_{i L i n e} \\
& {\left[\begin{array}{l}
v_{a b} \\
v_{b c} \\
v_{c a}
\end{array}\right]=\left[\begin{array}{lll}
m_{A b} & m_{B b} & m_{C b} \\
m_{A c} & m_{B c} & m_{C e} \\
m_{A a} & m_{B a} & m_{C a}
\end{array}\right]\left[\begin{array}{l}
v_{A B} \\
v_{B C} \\
v_{C A}
\end{array}\right]} \\
& i_{i L i n e}=m^{\mathrm{T}} i_{\mathrm{oLibe}} \\
& {\left[\begin{array}{l}
i_{A B} \\
i_{B C} \\
i_{C A}
\end{array}\right]=\left[\begin{array}{lll}
m_{A b} & m_{A c} & m_{A a} \\
m_{B b} & m_{B c} & m_{B a} \\
m_{C b} & m_{C e} & m_{C a}
\end{array}\right]\left[\begin{array}{l}
i_{b b} \\
i_{b c} \\
i_{c a}
\end{array}\right]}
\end{aligned}
$$

where 


$$
\begin{aligned}
& m_{A b}=\frac{f}{f}\left(M_{A a}-M_{A b}\right)-\frac{f}{f}\left(M_{B a}-M_{B b}\right) \\
& m_{B b}=\frac{1}{3}\left(M_{B a}-M_{B b}\right)-\frac{1}{3}\left(M_{C a}-M_{C a}\right) \\
& m_{C b}=\frac{1}{3}\left(M_{C a}-M_{C b}\right)-\frac{1}{3}\left(M_{A a}-M_{A b}\right) \\
& m_{\text {dc }}=f\left(M_{A b}-M_{A c}\right)-\frac{1}{3}\left(M_{M b}-M_{M_{c}}\right) \\
& m_{B C}=f\left(M_{B b}-M_{B C}\right)-\frac{1}{3}\left(M_{C D}-M_{C C}\right) \\
& m_{C \mathrm{C}}=\frac{1}{f}\left(M_{C b}-M_{C C}\right)-\frac{1}{f}\left(M_{A b}-M_{A c}\right) \\
& m_{A a}=\frac{1}{3}\left(M_{A i}-M_{A a}\right)-\frac{1}{3}\left(M_{B i}-M_{B a}\right) \\
& m_{B d}=\frac{1}{3}\left(M_{B_{c}}-M_{B_{a}}\right)-\frac{f}{f}\left(M_{C \mathrm{C}}-M_{C a}\right) \\
& m_{C i t}=\frac{1}{3}\left(M_{C e}-M_{C a}\right)-\frac{1}{3}\left(M_{A v}-M_{A a}\right)
\end{aligned}
$$

\section{FIELD ORIENTED CONTROLLER}

The field-oriented control strategy was implemented in the matrix converter induction motor drive. The induction machine is controlled in synchronously rotating $\mathrm{d}-\mathrm{q}$ axis frame with the $\mathrm{d}$ axis oriented along the stator flux vector position. In this way, a decoupled control between the electrical torque and the rotor excitation current is obtained. The indirect field oriented control technique using impressed voltages and control of field and torque current components was implemented in the drive system. The control requires the measurements of the stator currents and the rotor position. Equations (17), (18), and (19) are the fundamental equations for field oriented control [18], and allow the induction motor to act like a separately excited d.c. machine with decoupled control of torque and flux, making it possible to operate the induction motor as a high-performance four quadrant servo drive.

$$
\begin{aligned}
& i_{\text {sd }}=\tau_{\mathrm{r}} \frac{\mathrm{d} i_{\text {mrd }}}{\mathrm{d} t}+i_{\text {mard }} \\
& \omega_{\mathrm{si}}=\left(\frac{1}{\tau_{\mathrm{r}} i_{\text {mad }}}\right) i_{\text {sq }} \\
& T_{e}=3\left(\frac{P}{2}\right) \frac{L_{0}^{2}}{L_{r}} i_{s d} i_{s q}
\end{aligned}
$$

Figure 3 shows a schematic block diagram for the field-oriented controlled matrix converter induction motor drive where three output currents and rotor position are required to be measured. The field-oriented control method shown in Fig. 3 imposes a rotor flux vector angle $\square$ e which is aligned to the $\mathrm{d}$ axis. The motor speed, $\omega_{\mathrm{r}}$ is measured and compared with the demanded speed $\omega_{\mathrm{r}^{*}}$. The resulting speed error is then processed by a proportional-integral (PI) controller to produce an $\mathrm{i}_{\mathrm{sq}^{*}}$ demand, which in the constant torque region is proportional to the torque demand, providing that the system is field-oriented. The flux current demand is maintained constant at just under saturation level when the machine runs below synchronous speed. However, field weakening must be introduced above synchronous speed at base frequency operating conditions so that the flux current reference is reduced as the speed is increased above its synchronous base.

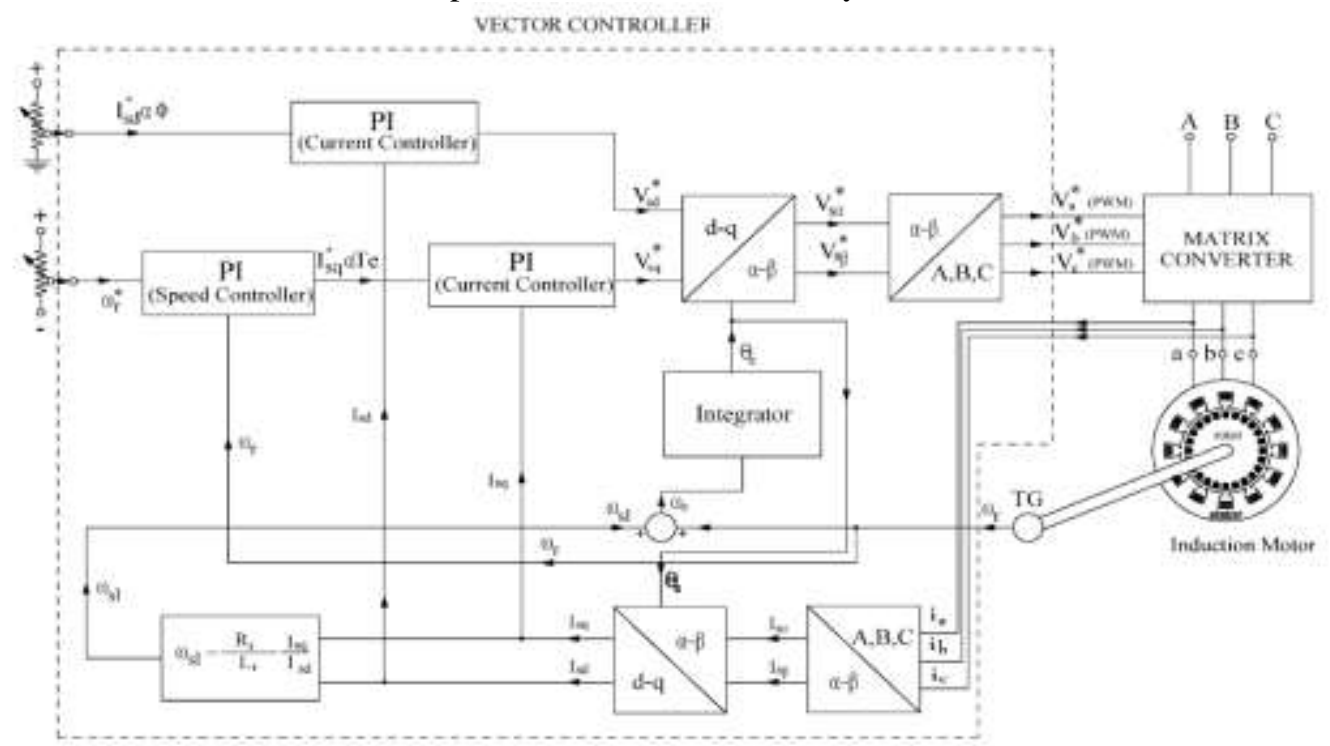

Fig. 3. Block diagram for vector controlled matrix converter induction motor drive using PI controllers The transformation of the instantaneous stator currents into field-oriented $\mathrm{d}$ and $\mathrm{q}$ axis components is carried out in two stages. First, the three instantaneous currents $i_{s a}(t), i_{s b}(t)$, and $i_{s c}(t)$ are transformed to the stationary two axis currents, $i_{s a}(t)$ and $i_{s b}(t)$. These are then transformed into the rotating $d-q$ axis currents, $i_{s d}$ and $i_{s q}$. The 
equivalent complex operator $\mathrm{e}^{-\mathrm{j} \sqcap \mathrm{e}}$ is used in this transformation. $\square \mathrm{e}$ denotes the instantaneous flux vector angle, which is determined by summing the rotor position signal and the commanded slip position obtained by integrating Eq. (18). The inverse transformation of $\mathrm{d}$ and $\mathrm{q}$ axis values to the instantaneous stator reference frame is represented by the complex operator $\mathrm{e}^{-\mathrm{j} \square \mathrm{e}}$. The two current controllers which employ PI control process the $i_{s d}$ and $i_{s q}$ errors to give $V$ ' ${ }_{s d}$ and $V^{\prime}$ sq. Voltage compensation terms are added to the output of each current controller to get the resulting voltage reference signals $\mathrm{V}_{\mathrm{sd} *}$ and $\mathrm{V}_{\mathrm{sq}}$. These voltages are then converted to the three-phase voltages using the complex operator $\mathrm{e}^{-\mathrm{j} \square \mathrm{e}}$. The three-phase voltages $\mathrm{V}_{\mathrm{a}^{*}}, \mathrm{~V}_{\mathrm{b}^{*}}, \mathrm{~V}_{\mathrm{c}^{*}}$, and

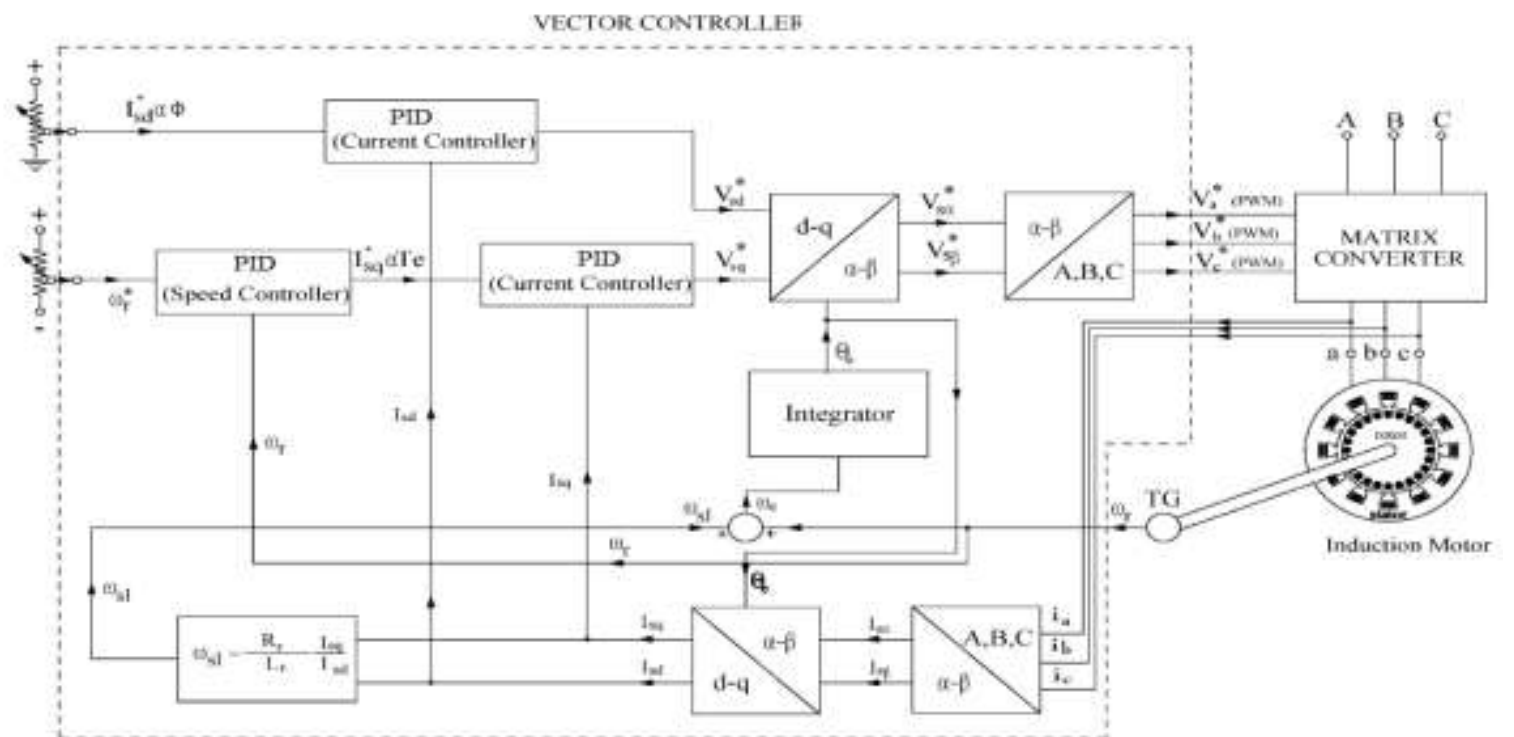

Fig. 4. Block diagram for vector controlled matrix converter induction motor drive using PID controllers

instantaneous flux vector angle $\square$ e are used as the input signals for the Venturini algorithm (Equations. 1, 2, 3, $4,5,6,7,8,9,10,11)$ to generate the duty cycles for each switch in the matrix converter. Figure 4 shows the same schematic block diagram for the field-oriented controlled matrix converter induction motor drive but PID controllers are use instead of PI controllers.

\section{V. d-q MODEL OF INDUCTION MOTOR}

The simulation equations for an induction motor in the $\mathrm{d}-\mathrm{q}$ synchronously rotating reference frame are given as [11]

$$
\begin{aligned}
& {\left[\begin{array}{c}
V_{\mathrm{sq}} \\
V_{\mathrm{sd}} \\
0 \\
0
\end{array}\right]=\left[\begin{array}{cccc}
R_{\mathrm{s}} & 0 & 0 & 0 \\
0 & R_{\mathrm{s}} & 0 & 0 \\
0 & 0 & R_{\mathrm{r}} & 0 \\
0 & 0 & 0 & R_{\mathrm{f}}
\end{array}\right]\left[\begin{array}{c}
I_{\mathrm{sq}} \\
I_{\mathrm{sd}} \\
I_{\mathrm{rq}} \\
I_{\mathrm{rd}}
\end{array}\right]} \\
& +\left[\begin{array}{cccc}
p & \omega_{s} & 0 & 0 \\
-\omega_{s} & p & 0 & 0 \\
0 & 0 & p & \left(\omega_{s}-\omega_{r}\right) \\
0 & 0 & -\left(\omega_{s}-\omega_{r}\right) & p
\end{array}\right]\left[\begin{array}{l}
\psi_{s q} \\
\psi_{\text {sd }} \\
\psi_{r q} \\
\psi_{r d}
\end{array}\right] \\
& {\left[\begin{array}{l}
\psi_{\mathrm{sq}} \\
\psi_{\mathrm{sd}} \\
\psi_{\mathrm{rq}} \\
\psi_{\mathrm{rd}}
\end{array}\right]=\left[\begin{array}{cccc}
L_{\mathrm{s}} & 0 & L_{\mathrm{o}} & 0 \\
0 & L_{\mathrm{s}} & 0 & L_{\mathrm{o}} \\
L_{0} & 0 & L_{\mathrm{r}} & 0 \\
0 & L_{0} & 0 & L_{\mathrm{r}}
\end{array}\right]\left[\begin{array}{l}
I_{\mathrm{sq}} \\
I_{\mathrm{sd}} \\
I_{\mathrm{rq}} \\
I_{\mathrm{rd}}
\end{array}\right]} \\
& L_{\mathrm{s}}=L_{\mathrm{is}}+L_{\mathrm{o}} \\
& L_{\mathrm{r}}=L_{\mathrm{ir}}+L_{\mathrm{o}} \\
& T_{\mathrm{c}}=3 \frac{P L_{\mathrm{o}}}{2}\left(I_{\mathrm{s \textrm {Q }}} \psi_{\mathrm{nd}}-I_{\mathrm{sd}} \psi_{\mathrm{rq}}\right) \\
& J \frac{\mathrm{d} \omega_{\text {mexb }}}{\mathrm{d} t}=T_{\epsilon}-T_{\mathrm{L}}-f_{\mathrm{v}} \omega_{\text {maxh }}
\end{aligned}
$$


where quantities with subscript $\mathrm{q}$ or $\mathrm{d}$ denote $\mathrm{q}$ axis or $\mathrm{d}$ axis quantities and quantities with subscript $\mathrm{s}$ or $\mathrm{r}$ denote stator or rotor quantities. $\Psi$ denotes flux linkage, $\mathrm{R}$ is resistance, $\mathrm{L}_{\mathrm{ls}}$ and $\mathrm{L}_{\mathrm{lr}}$ are the stator and rotor leakage inductances, respectively, and $\mathrm{L}_{\mathrm{o}}$ is the magnetizing inductance. $\mathrm{L}_{\mathrm{s}}$ and $\mathrm{L}_{\mathrm{r}}$ denote the self inductances of the stator and rotor, respectively. $\mathrm{T}_{\mathrm{e}}$ and $\mathrm{T}_{\mathrm{L}}$ are the motor torque and load torque, respectively. $\mathrm{P}$ is the number of poles, and $\mathrm{f}_{\mathrm{v}}$ is the friction constant coefficient. J is inertia and $\omega_{\text {mech }}$ is the mechanical speed of the motor. All rotor quantities are referred to the stator.

\section{SIMULATION RESULTS}

The simulation program constructed in Matlab/Simulink software package [19] comprises three main parts which are the matrix converter, induction motor, and field-oriented controller . The simulation results of various parameters related to the performance of an induction motor are presented.

Figure 5 shows the comparison of performance for the speed control of induction motor for both PI and PID control scheme in which blue line shows the desired speed whereas the red line shows the actual one. From the figure we can see that though the fluctuation of actual speed from desired in PID control is more compare to PI scheme, but in the PID scheme speed of motor stabilizes quickly near to the desired speed.

Figure 6 shows simulation result of stator current of induction motor for PI and PID control It shows that the demand of stator current is decrease in PID scheme. For example take instance of $4 \times 10^{4}$ sample of time in which the demand of stator current in PI control method is $4163 \mathrm{~mA}$ (approx.), whereas for the same instance for PID control it is $4091 \mathrm{~mA}$ (approx.). So we get decrement of approximately $72 \mathrm{~mA}$ demand of stator current in PID control method compare to PI control.

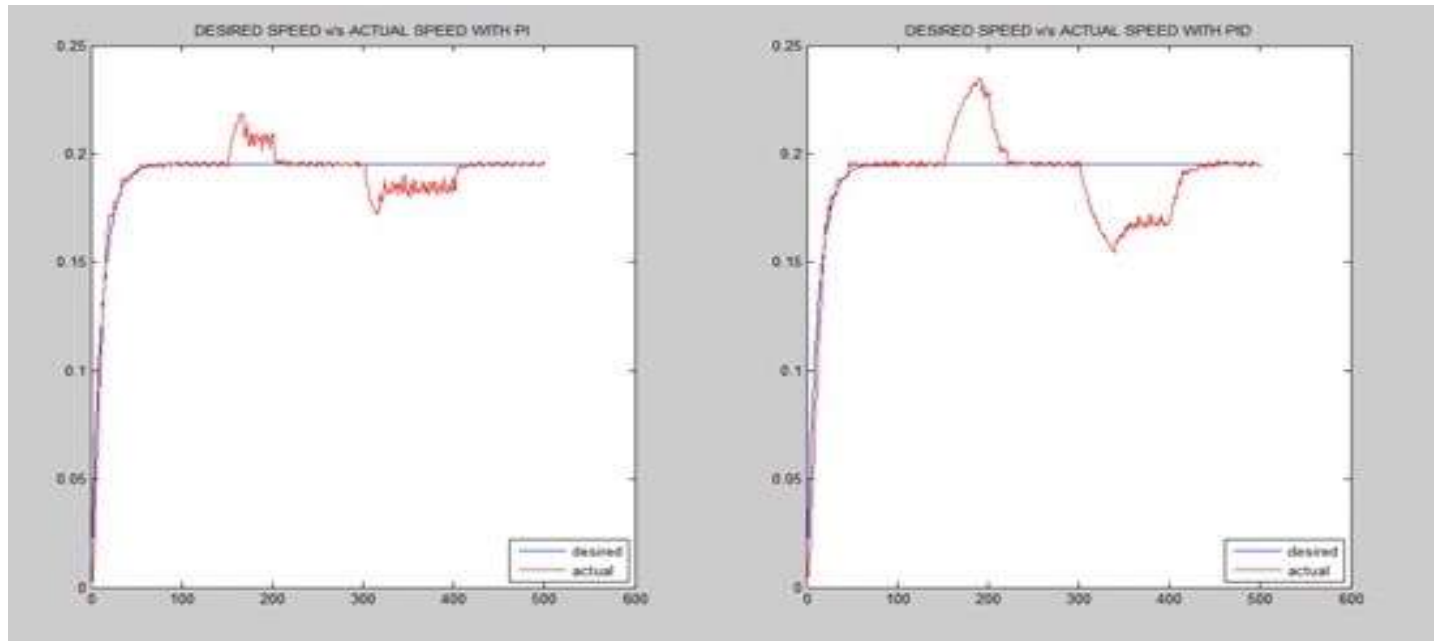

Fig.5. Speed Control of Induction Motor


Fig.6. Stator Current of Induction Motor 
Figure 7 shows the performance comparison of PWM duty cycle between PI and PID control schemes, which shows that there is smooth variation in amplitude of pulses in PID control method as compare to the PI one. Figure 8 clearly shows that the TDH(Total Harmonic Distortion) is $2.687 \%$ in PID control method, whereas in PI control it is $2.866 \%$. So we get a good improvement in total harmonic distortion in PID control scheme.

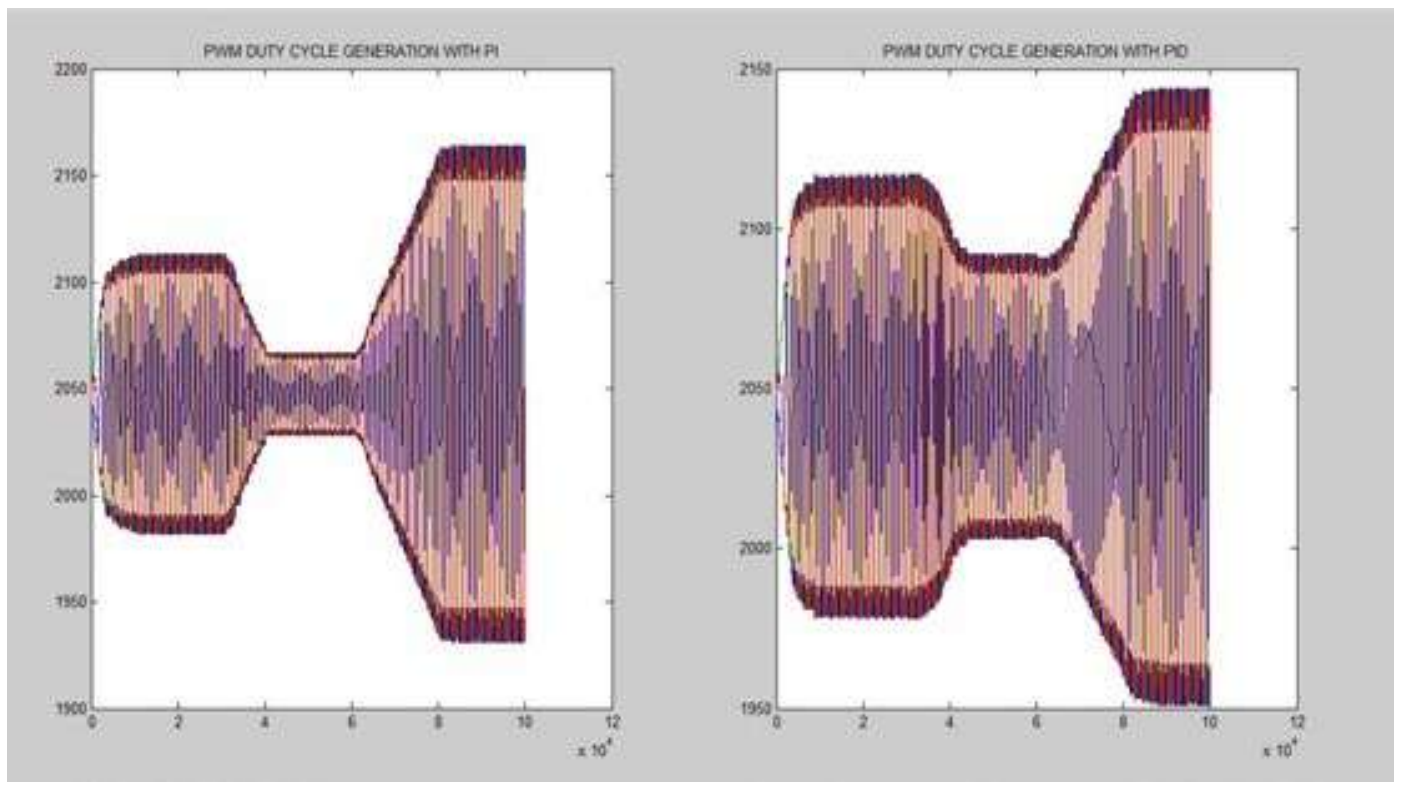

Fig.7. PWM Duty Cycle

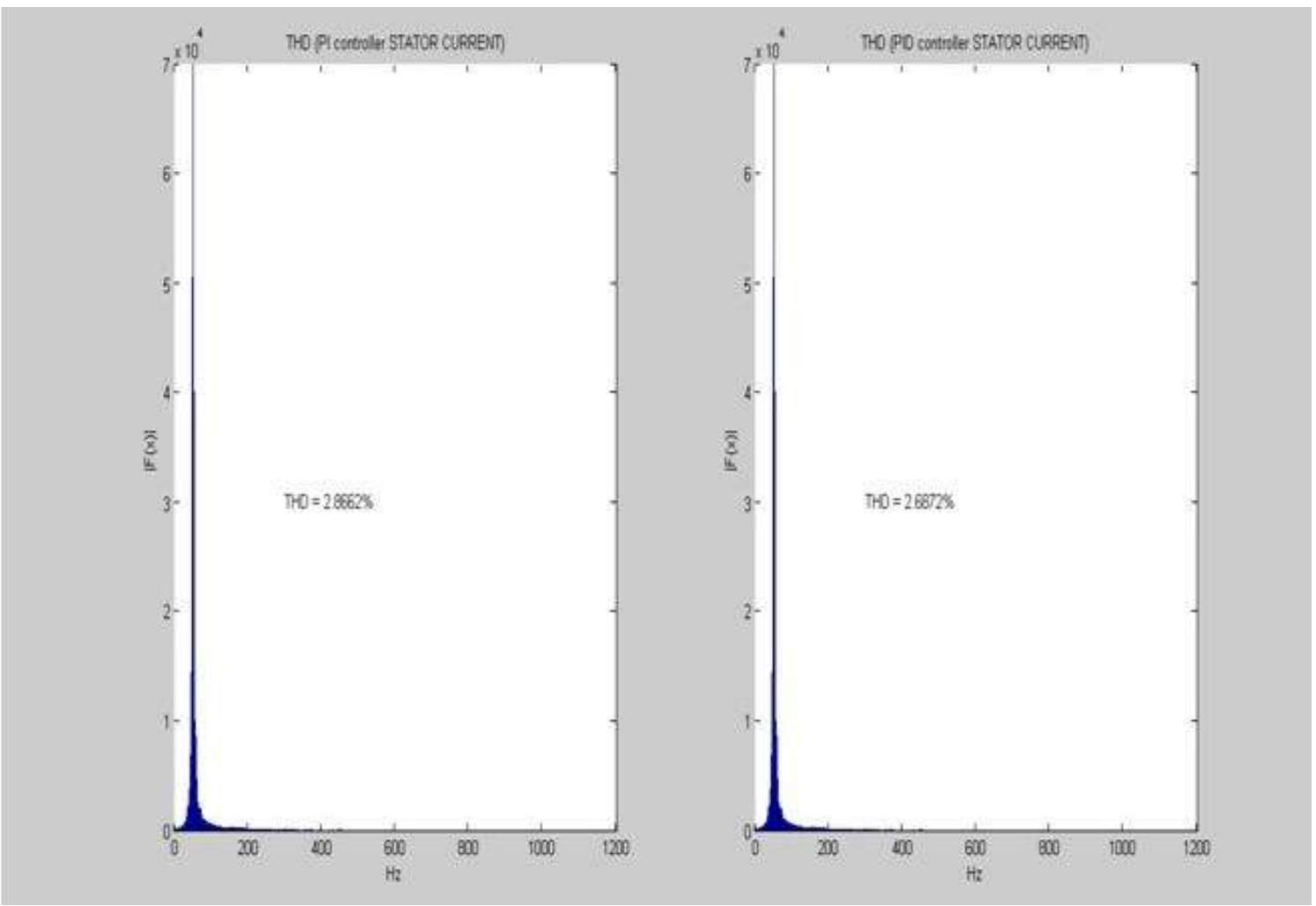

Fig.9. Total Harmonic Distortion

VII. CONCLUSION

For this paper, firstly modeling and simulation is done for the matrix converter-fed induction motor drive using PI control, then same simulation is done by using PID control. Simulation results shows that some parameters like torque demand and rotor angle of induction motor is almost same in both control scheme, but the performance of motor is significantly improved in PID control compare to PI control scheme if we consider 
parameters of induction motor like speed control, stator current demand, PWM duty cycle and TDH(Total Harmonic Distortion). Briefly, in performance comparison between PI and PID control of matrix converter fed induction motor drive we can conclude that in PID control scheme speed of motor stabilizes quickly near to the desired speed, stator current demand is less, amplitude variation is smooth in PWM duty cycle and TDH is much less in comparison to PI control.

\section{REFERENCES}

[1] L.Gyugi and B.R.Pelly, Static Power Freuency Changers, New York : Wiley-Interscience 1976.

[2] A.Alesina and M.Venturini,"Solid state power conversion : A Fourier analysis approach to generalized transformer synthesis" IEEE Transaction on Circuit systems, Vol. CAS-28, No.4, 1981, pp 319-330.

[3] A. Alesina, M.G.B.V., "Analysis and Design of Optimum-Amplitude Nine - Switch Direct AC-AC Converters." IEEE Trans. On Power. Electronic, 4 (1989)

[4] D. Casadei, G.S., A. Tani, and L. Zari, "Matrix Converters Modulation Strategies: A New General Approach Based on SpaceVector Representation of the Switch State." IEEE Trans. on Industrial Electronic, 49(2) (2002)

[5] P. W. Wheeler, J.R., J. C. Claire, L.Empringham, A. Weinstein, "Matrix Converters : A Technology Review." IEEE Trans. on Industrial Electronic, 49(2) (2002)

[6] Ruzlaini Ghoni, Ahmed N.Abdalla, Zulkarnain Lubis, Mohd Nuhairi, Mohd Yusri "Performance Analysis of Difference Matrix Converter Topologies on Three Phase Induction Motor Drives", in 2nd International Conference On Engineering Technology, 2009

[7] Empringham L, Wheeler PW, Clare JC (1998) Intelligent commutation of matrix converter bi-directional switch cells using novel gate drive techniques. In: IEEE PESC'98, Fukuoka, Japan, 17-22 May. IEEE, Piscataway, N.J., pp 707-713

[8] Chang J, Sun T, Wang A (2002) Highly compact AC-AC converter achieving a high voltage transfer ratio. Proc IEEE Trans Ind Electron 49:345-352

[9] Klumpner C, Nielson P, Boldea I, Blaabjerg F (2002) A new matrix converter motor (MCM) for industry applications. Proc IEEE Trans Ind Electron 49:325-335

[10] Simon O, Mahlein J, Muenzer MN, Bruckmann M (2002) Modern solutions for industrial matrix-converter applications. Proc IEEE Trans Ind Electron 49:401-406

[11] Zuckherberger A, Weinstock D, Alexandrovitz A (1996) Simulation of three-phase loaded matrix converter. IEE Proc Trans Electr Power Applic 143:294-300

[12] Zuckherberger A, Weinstock D, Alexandrovitz A (1997) Single-phase matrix converter. IEE Proc Trans Electr Power Applic 144:235-240

[13] Sunter S, Altun H, Clare JC (2002) A control technique for compensating the effects of input voltage variations on matrix converter modulation algorithms. Electric Power Components Syst 30:807-822

[14] Matsuo T, Bernet S, Colby RS, Lipo TA (1998) Modeling and simulation of matrix converter/induction motor drive. Math Comput Simul 46:175-195

[15] Bouchiker S, Capolino GA, Poloujadoff M (1998) Vector control of a permanent-magnet synchronous motor using AC-AC matrix converter. Proc IEEE Trans Power Electron 13:1089-1099

[16] Alesina A, Venturini M (1981) Solid-state power conversion: a Fourier analysis approach to generalized transformer synthesis. Proc IEEE Trans Circuit Syst 28:319-330

[17] Sünter S (1995) A vector controlled matrix converter induction motor drive. PhD Thesis, Department of Electrical and Electronic Engineering, University of Nottingham.

[18] Leonhard W (1985) Control of electrical drives. Springer, Berlin Heidelberg New York

[19] Math Works (2009) MATLAB_for Microsoft Windows. Math Works, Mass.

[20] H. Altun and S. Sunter, "Matrix converter induction motor drive: modeling, simulation and control" Electrical Engineering (2003) 86: 25-33 DOI 10.1007/s00202-003 0179-1 Springer-Verlag 2003 